\title{
Erratum to: PMMA embolization to the left dorsal foot artery during percutaneous vertebroplasty for spinal metastases
}

Iliopoulos Panagiotis - Korovessis Panagiotis •

Vitsas Vasilios

Published online: 11 August 2013

(c) Springer-Verlag Berlin Heidelberg 2013

\section{Erratum to: Eur Spine J}

\section{DOI 10.1007/s00586-013-2919-x}

The authors' given names and family names were transposed; their correct names are as shown here:

P. Iliopoulos and the other family names are P. Korovessis and V. Vitsas.

The online version of the original article can be found under doi:10.1007/s00586-013-2919-x.

I. Panagiotis $(\bowtie)$

Radiology Department, Patras General Hospital,

Tsertidou 1, Achaia, Patra, Greece

e-mail: eliopan1@gmail.com

K. Panagiotis · V. Vasilios

Orthopedic Department, Patras General Hospital,

Tsertidou 1, Achaia, Patra, Greece

e-mail: korovess@otenet.gr 